\title{
A Novel Procedure for Protection Setting in an HVDC System Based on Fault Quantities
}

\author{
Benfeng Gao *, Ruixue Zhang ${ }^{\dagger}$ and Xuewei Zhang*
}

\begin{abstract}
HVDC protection setting is difficult to be calculated analytically because of its strong nonlinearity. The currently used setting method is based on the empirical setting of previous projects and then verified by digital simulation. It entails a huge workload and low efficiency. To facilitate protection setting, this paper systematically summarizes the HVDC protection characteristics and then presents a classification of HVDC protections according to the protection principles. On the basis of the fault quantities, a novel setting procedure suitable for travelling wave protection, derivative and level protection, and differential protection is proposed. The proposed procedure is illustrated and verified in detail with the example of travelling wave protection. An HVDC protection setting system that has the functions of automatic protection setting and data management is developed utilizing the $\mathrm{C} \#$ programming language.
\end{abstract}

Keywords: HVDC, Protection setting, Procedure, Fault quantities, PSCAD/EMTDC

\section{Introduction}

With the advantages of transmission capacity, transmission distance, power control flexibility, and interconnectivity between power systems, high-voltage direct-current (HVDC) transmission systems have been widely applied all over the world [1]. The integration of large-scale renewable energy sources into electrical grids would especially benefit from the use of HVDC technology [2,3].

In China, HVDC transmission has been the principal form of bulk power transmission. At present, 24 HVDC transmission lines, of which 16 belong to the State Grid Corporation of China and 8 to the China Southern Power Grid, are in operation or under construction. Some typical projects, including the project of Xiangjiaba to Shanghai (XS project) and the project of Hami to Zhengzhou, have introduced many technical innovations, such as expansion of transmission capacity, reduction in energy consumption, and development of critical equipment. A giant $\mathrm{AC} / \mathrm{DC}$ grid based on a high-voltage transmission grid structure will be constructed in approximately 2020 and the power transmitted from western to eastern will be more than $150 \mathrm{GW}$. Along with the rapid development of HVDC transmission systems, the number of fault occurrences is rising, which has an extremely adverse impact on the operation of the entire grid.

Control and protection systems are a vital part of an HVDC system to guarantee the safety, reliability, and stability of its operation [4-6]. The protection settings are critical to these systems. However, for an HVDC system,

$\dagger \quad$ Corresponding Author: Dept. of Electrical Engineering, North China Electric Power University, China. (rxzncepu@163.com)

* Dept. of Electrical Engineering, North China Electric Power University, China. (gaobenfeng@126.com)

Received: March 19, 2016 ; Accepted: November 22, 2016 the general setting procedure is not as mature as in its $\mathrm{AC}$ counterpart. Due to the rapid regulation of the control system, the fault response characteristics of an HVDC system are extremely complex. Therefore, the fault limit setting, which is used to determine the protection setting in an HVDC system, is difficult to be calculated through fault analysis.

At present, the protection setting in an HVDC system is determined by a combination of empirical setting and simulation verification. The existing researches mainly focus on novel protection methods, the analysis of refusal operation and maloperation, and the protection configuration of hardware and software [7-11]. The use of voltage travelling wave protection to remedy the difficulty in quickly distinguishing internal faults and external faults is proposed in [12]. The technique is based on wavelet transformation and an analysis of the energy spectrum. In [13], a reliable protection system with extremely long transmission lines is demonstrated, which is able to make all protection decisions solely on the basis of local detection. A digital overcurrent relay with a novel characteristic for HVDC converter protection is developed in [14]. A recent work [15] introduces a complicated DC line fault that occurred in the $\pm 800 \mathrm{kV}$ Chu-Sui HVDC transmission system. It shows that irrational setting in the DC filter differential protection impacts the fault clearance. Protection configuration of the hardware and software in an HVDC system is introduced in [16]. On the basis of the preparative parameters of the setting, a setting method is proposed in [17], however it can only be used for certain protections with low universality.

From the foregoing survey, it is apparent that there is no general procedure for protection setting in an HVDC system at present. Considering multiple real HVDC 
projects, the protection setting procedure is evaluated in this paper. The main contributions of this paper are 1) the classification of HVDC protections on the basis of protection theory, 2) a novel general protection setting procedure based on fault quantities, and 3) an automatic protection setting program for HVDC system.

This paper is organized as follows. Section 2 describes the classification of HVDC protections. A detailed description of protection setting procedure for an HVDC system based on fault quantities is given in Section 3. In Section 4 , the procedure is illustrated with the example of travelling wave protection in a real project. Section 5 introduces the design philosophy and main functions of an HVDC protection setting system. Finally, the conclusions are given in Section 6.

\section{Classification of HVDC Protections}

Due to the complexity of the HVDC protection principle, determining the setting procedure for each protection entails not only a heavy workload but also a low efficiency. To overcome this issue, HVDC protections need to be classified into different categories, and then a general setting procedure for each category can be devised. The following two different classifications of HVDC protections will be discussed.

\subsection{Classification based on location}

The traditional classification of HVDC protections is given in the form of protection subareas according to location. Protections located at the same place are classified into one protection subarea.

Fig. 1 shows the protection subareas of an HVDC system, which includes converter protection, pole protection, and bipolar protection. In the same protection subarea, all protections share the same location, however their protection

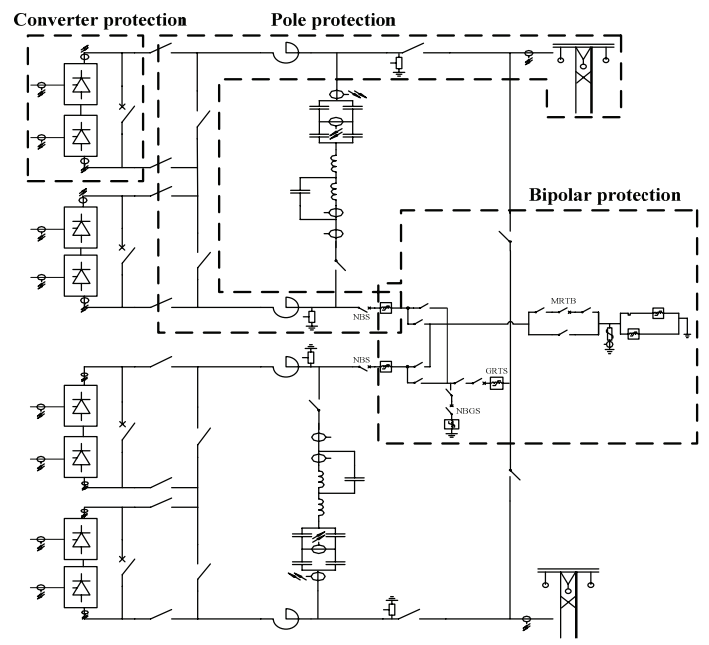

Fig. 1. Protection subareas of an HVDC system. theories and setting methods are different. Hence, it is difficult to formulate a general procedure for protection setting through protection subareas. For example, the pole protection subarea consists of pole bus differential protection, pole overload protection, and neutral bus switch protection. A general setting procedure suitable for these three protections cannot be developed because their protection theories are different.

In this paper, the classification based on protection principles is proposed to devise a general setting procedure for the same type of protections.

\subsection{Classification based on the protection principle}

Protections sharing the same or similar protective principle have many similarities in their protection setting. Therefore, it is essential to classify HVDC protections on the basis of the protective principle to develop a general setting procedure. According to a detailed analysis, all HVDC protections can be classified into six categories: travelling wave protection, derivative and level protection, differential protections, overload protections, switch protections, and other protections. The details are shown in Table 1.

The transmission line is the center of an HVDC system, including the main protections of travelling wave protection and derivative and level protection [18]. These two protections share the same protective principles and differences from the other protections. Differential protections comprise one third of all HVDC protections, and their protective zones are the locations where they can operate quickly as the main protection. Hence, all differential protections are classified into one category. Overload protections share the same theory, and their common purpose is to protect equipment from damage caused by overload [14]. Switch protections are classified into one category because of their relevance to the switch characteristic. The other protections, sharing little in common with each other and having different protective theories, are classified as other protections.

Overload protections, switch protections, and other protections are mostly applied to reflect the operating condition of the equipment. It is difficult to calculate the operating condition in advance. The protection setting of these protections always relies on empirical setting and operational experience, and therefore a general setting procedure for these three categories of protections cannot be obtained.

Travelling wave protection, derivative and level protection detect ground faults on a transmission line by measuring the DC line voltage and DC line current [10]. Differential protection detects a ground fault, where the protection is located by measuring the differential current. These three categories of protections are all set to eliminate certain faults. Because of their similar protection purpose and principle, a general setting procedure for these 
Table 1. Classification of HVDC protections.

\begin{tabular}{|c|c|c|c|}
\hline & Converter protections & Pole protections & Bipolar protections \\
\hline $\begin{array}{c}\text { Travelling wave } \\
\text { protection }\end{array}$ & & Travelling wave protection & \\
\hline $\begin{array}{l}\text { Derivative and level } \\
\text { protections }\end{array}$ & & Derivative and level protection & \\
\hline \multirow{6}{*}{ Differential protections } & \multirow{2}{*}{ Valve short circuit protection } & DC line differential protection & \multirow{2}{*}{$\begin{array}{c}\text { Bipolar neutral bus differential } \\
\text { protection }\end{array}$} \\
\hline & & Pole bus differential protection & \\
\hline & \multirow[b]{2}{*}{ Converter overcurrent protection } & Neutral bus differential protection & \multirow{2}{*}{$\begin{array}{l}\text { Metallic return transverse } \\
\text { differential protection }\end{array}$} \\
\hline & & $\begin{array}{l}\text { HV/LV converter connection bus } \\
\text { differential protection }\end{array}$ & \\
\hline & \multirow{2}{*}{ Commutation failure protection } & Pole differential protection & \multirow{2}{*}{$\begin{array}{l}\text { Metallic return longitudinal } \\
\text { differential protection }\end{array}$} \\
\hline & & DC filter differential protection & \\
\hline \multirow{5}{*}{$\begin{array}{l}\text { Overload } \\
\text { protections }\end{array}$} & \multirow{2}{*}{ Converter overcurrent protection } & Pole overcurrent protection & \multirow{2}{*}{$\begin{array}{l}\text { Station ground overcurrent } \\
\text { protection }\end{array}$} \\
\hline & & DC overvoltage protection & \\
\hline & \multirow{2}{*}{ Voltage stress protection } & DC filter capacity unbalanced protection & \multirow{2}{*}{$\begin{array}{c}\text { Backup station ground overcurrent } \\
\text { protection }\end{array}$} \\
\hline & & DC filter resistance overload protection & \\
\hline & Bypass pair overload protection & Electrode line open circuit protection & Electrode line overload protection \\
\hline Switch protections & Bypass switch protection & Neutral bus switch protection & Transfer breaker protections \\
\hline \multirow{6}{*}{ Other protections } & High angle supervision & \multirow{2}{*}{ DC undervoltage protection } & \multirow{3}{*}{ Electrode line unbalance protection } \\
\hline & Thyristor monitoring & & \\
\hline & Valve misfire protection & \multirow{2}{*}{ Unbalanced operation protection } & \\
\hline & Low AC voltage detection & & \multirow{3}{*}{$\begin{array}{l}\text { Metallic return conductor ground } \\
\text { fault protection }\end{array}$} \\
\hline & \multirow{2}{*}{$\begin{array}{c}\text { Converter transformer valve side } \\
\text { neutral shift protection }\end{array}$} & DC harmonic protection & \\
\hline & & AC/DC line touch supervision & \\
\hline
\end{tabular}

protections can be obtained.

Aiming at the setting of travelling wave protection, derivative and level protection, and differential protections, this paper proposes a novel setting procedure based on fault quantities.

\section{Procedure for Protection Setting Based on Fault Quantities}

Fault quantities are defined as electrical parameters that have obvious change trends and rapidly reflect the fault characteristics after a fault. In the AC protection setting procedure, some parameters must be determined or calculated at first, such as the maximum short circuit current, short circuit voltage, and differential current. These parameters are the fault quantities of the AC system. The protection criteria and setting of the AC protections are formulated and calculated on the basis of the chosen fault quantity. The setting method of AC protections is suitable for the protections designed for eliminating faults.

Learning from the idea of AC protection setting, this paper applies the concept of fault quantities to an HVDC system and proposes a procedure for HVDC protection setting. The typical fault quantities in an HVDC system include the DC voltage, DC current, the change rate of the DC voltage, and the differential current [17]. Due to the complex function of the HVDC control system, these fault quantities cannot be analytically calculated. Digital simulation is widely employed in the research of HVDC protection setting.

On the basis of the fault quantities, the procedure for

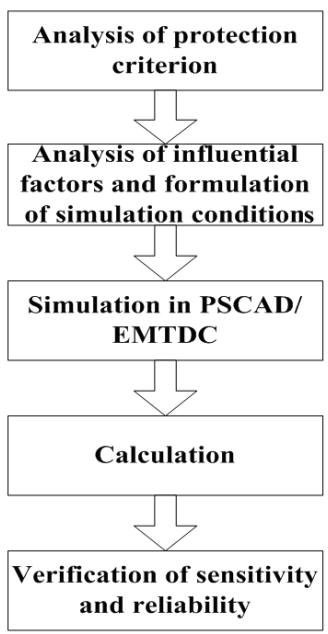

Fig. 2. Procedure for HVDC protection setting.

HVDC protection setting is shown in Fig. 2, which consists of five steps.

Step 1. Analysis of protection criterion

The protection criterion has already been determined in real HVDC protections. Protection setting is the core of the protection criterion. Therefore, the fault quantities should be derived from an analysis of the protection criterion. To simplify the calculation, the form of the fault quantities should be similar to that of the protection criterion.

Step 2. Analysis of influential factors and formulation of simulation conditions

This step is the core part of the procedure for HVDC protection setting. The influential factors include the 
operational mode, fault distance, and ground resistance. There are two aspects to the analysis of the influential factors: one is to analyze the variation trend of the fault quantities during the fault, and the other is to generalize the change trends of the fault quantities under different types of faults. Through the above analysis, the key influential factors of protection setting can be determined.

According to the analysis of the key influential factors, the simulation conditions are determined by the extent to which these factors affect the protection setting. In general, a minor fault has a greater impact on the setting than a serious fault. Therefore, the formulation of the simulation conditions should mainly consider all types of minor faults. For example, if a large ground resistance has a significant impact on a protection, the simulation conditions should include some faults of the large resistance.

Step 3. Simulation in PSCAD/EMTDC

PSCAD/EMTDC (Power Systems Computer-Aided Design/Electromagnetic Transients including DC) is one of the most authoritative and universal electromagnetic transient simulation software programs in the world. EMTDC is the calculation core, whereas PSCAD provides a graphical operation interface. PSCAD/EMTDC uses time domain analysis to solve integral and differential equations in power systems [15].

According to the simulation conditions determined in step 2, the data of the fault quantities are acquired by simulation in PSCAD/EMTDC. To increase the efficiency and achieve automatic setting, the component named "multiple run" in PSCAD/EMTDC is applied to control an iterative simulation. This component can manipulate variables including fault types, fault distance, and the parameters of the operational mode from one run to the next. The data of the fault quantities in every run are stored for the setting calculation.

\section{Step 4. Calculation}

Different protections have different setting principles, and the calculation is based on these principles. For example, if the protection should operate when an internal fault occurs, the minimum internal fault quantity should be selected. If the protection should not operate when an external fault occurs, the maximum external fault quantity should be selected.

To take into consideration the measurement error, the selected fault quantity is multiplied by a confidence coefficient to obtain the protection setting.

Step 5. Verification of sensitivity and reliability

The protection setting calculated in step 4 is substituted into the simulation model of the protection built on the basis of the actual parameters and structure. Internal and external faults are set to verify the sensitivity and reliability of the protection setting. If the protection correctly operates in internal faults and does not operate in external faults, the protection setting can be determined [12].

\section{Application of Protection Setting Based on Fault Quantities}

In this section, taking the travelling wave protection of the XS project as an example, the application of the proposed procedure for protection setting is introduced in detail.

\subsection{Test system description}

The XS project is a demonstration $\pm 800 \mathrm{kV}$ UHVDC project in China. In July 2010, it was officially put into operation. The transmission capacity is up to $700 \mathrm{MW}$, with a transmission distance of $1907 \mathrm{~km}$.

The XS project is selected as the test system. The main circuit of XS HVDC project is built using PSCAD/ EMTDC components. The simulation time step is $80 \mu \mathrm{s}$. The structure of the simulation model is shown in Fig. 3, including the $\mathrm{AC}$ system, transformers, converters, valves, HVDC transmission lines, and AC and DC filters. The $\mathrm{AC}$ systems on the rectifier and inverter sides are both represented as Thevenin equivalent source with impedances. The main circuit parameters and operation modes are listed in Table A and B in the appendix, respectively.

To improve the simulation accuracy, the control and protection system of this model is derived from the real XS project, which is developed in HIDRAW language and provided by the HVDC equipment manufacturers. The principle and realization process of the interface technology between the PSCAD/EMTDC and HIDRAW can be found in literature [19]. In this way, the digital simulations based on real control are realized in PSCAD/EMTDC platform.

\subsection{Protection setting of travelling wave protection}

In accordance with the proposed procedure in Section 3, the following five steps are given.

\subsubsection{Analysis of protection criterion}

The travelling wave protection detects ground faults on

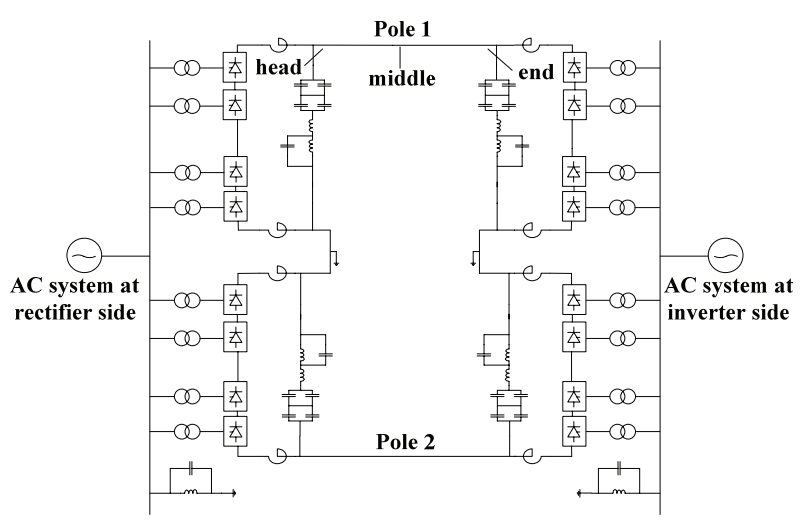

Fig. 3. Structure of test system. 
the transmission line by measuring the DC current and DC voltage. The protection criterion of the travelling wave can be expressed as (1):

$$
\left\{\begin{array}{l}
\frac{d P}{d t}>k_{1} \\
\Delta G_{w a v}>k_{2}
\end{array}\right.
$$

where $P$ is the pole wave, and $G_{\text {wav }}$ is the ground mode wave, both transformed from the measured DC current and DC voltage. The protection settings are $k_{l}$ and $k_{2}$.

The expressions for the pole wave and ground mode wave are given as (2) and (3), respectively:

$$
\begin{gathered}
P=Z_{\alpha} I_{d L}-U_{d L} \\
G_{w a v}=Z_{0}\left(I_{E L}+I_{C N 1}+I_{C N 2}\right) / 2-\left(U_{d L 1}+U_{d L 2}\right) / 2
\end{gathered}
$$

where $Z_{\alpha}$ is the pole wave impedance determined by the transmission line material, $Z_{0}$ is the ground mode wave impedance determined by the material of the earth conductor, $I_{d L}$ is the current of the DC transmission line, and $I_{E L}$ is the current of the earth electrode. $I_{C N 1}$ and $I_{C N 2}$ are the pole neutral capacitor currents of pole 1 and pole 2 , respectively. $U_{d L 1}$ and $U_{d L 2}$ are the DC voltages of pole 1 and pole 2 , respectively.

In Eq. (1), $d P / d t$ is used to detect ground faults on the HVDC transmission line. During steady-state operation, $d P / d t$ is close to zero, but it rapidly increases after faults occur. $\Delta G_{\text {wav }}$ is used to distinguish fault poles, eliminating disturbances from another pole on local pole protection. Travelling wave protection acts when $d P / d t$ and $\Delta G_{\text {wav }}$ both exceed their settings.

In view of this analysis, $d P / d t$ is selected as the fault quantity for travelling wave protection, and its setting will be determined by the setting procedure proposed in this paper.

As the criterion for distinguishing fault poles, $\Delta G_{w a v}$ can be selected by empirical setting and is verified if the setting can correctly discriminate the fault pole.

\subsubsection{Analysis of influential factors and formulation of simulation conditions}

The factors affecting the pole wave include the fault distance, ground resistance, and system operational modes [20]. The fault distance is the distance between the fault spot and the protection measurement spot.

$d P / d t$ is designed to detect various internal faults, and therefore the internal influential factors are analyzed [20]. In the real project, the sample frequency of the protection devices is $10 \mathrm{kHz}$. Instead of the differential method, the difference method is used to calculate $d P / d t$. The measurement spot is set at the head of the DC transmission line, which is shown in Fig. 3.

To analyze the characteristics of the pole wave, metallic ground faults at different distances, ground faults with different ground resistances, and ground faults in different operational modes are set in the simulation model.

As shown in Fig. 4, the pole wave has different characteristics under different conditions, which are crucial to the travelling wave protection setting. The conclusions obtained from Fig. 4 are as follows:

1) Fig. 4(a) indicates that with the increase in the distance between the fault spot and measurement point, the transmission time and loss of pole wave increase. Moreover, a high-frequency oscillation occurs when the fault location is close to the rectifier.

2) Fig. 4(b) shows that a pole wave is rapidly damped after a modest increase when the fault is located at the other pole.

3) Fig. 4(c) shows that a pole wave is significantly damped when the ground resistance increases.

4) Fig. 4(d) shows that pole wave is consistent in the same operation voltages. Fig. 4(e) shows that the pole wave at a low operation voltage is flatter than that a high operation voltage.

5) Fig. 4(f) shows that the outage of the pole 2 converters has little influence on the pole wave in pole 1 , but the outage of the pole 1 converters reduces the amplitude of the pole wave in pole 1 .

From the conclusions of the influential factor analysis, the formulation principles of the simulation conditions should consider the following aspects:

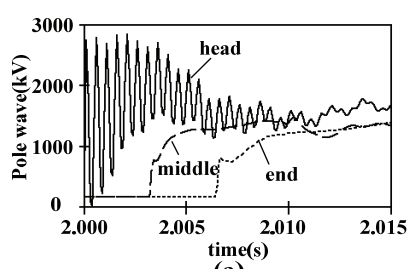

(a)

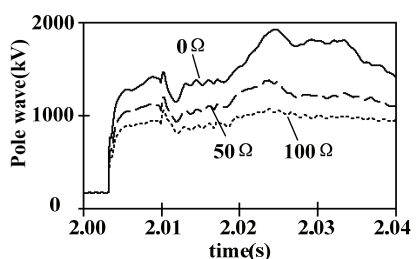

(c)

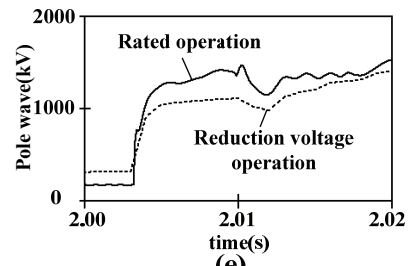

(e)

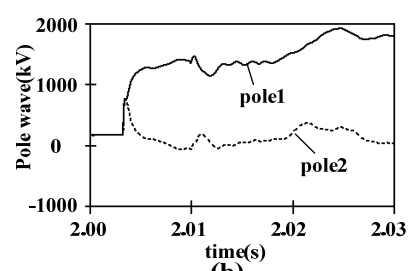

(b)

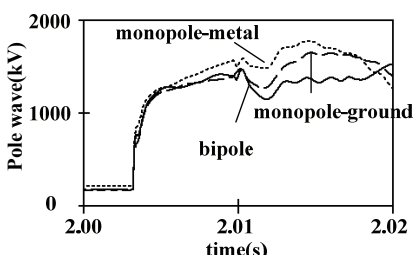

(d)

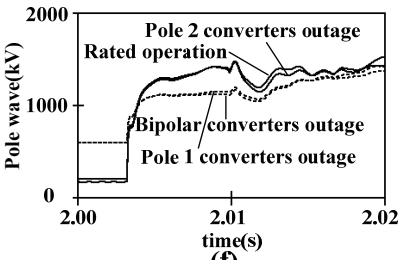

(f)
Fig. 4. Characteristics of pole waves under different conditions: (a) different fault distance; (b) different fault pole; (c) different ground resistance; (d) same operation voltage; (e) different operation voltage; and (f) different converter outage. 
1) The condition that faults take place far from the measurement point should be considered;

2) A large ground resistance should be set in the fault process;

3) Different operation voltages should be considered;

On the basis of the foregoing principles, the simulation conditions in PSCAD/EMTDC are formulated as follows:

1) Ten fault points with the same interval are set in the last half of the transmission line;

2) The ground resistance is $100 \mathrm{ohm}$;

3) The operational modes of bipole $800 \mathrm{kV}$, monopoleground, monopole-metal, bipole $400 \mathrm{kV}$, and one pole $400 \mathrm{kV}$ and the other $800 \mathrm{kV}$ are selected.

\subsubsection{Simulation in PSCAD/EMTDC}

The parameters of the different faults and different operation modes are set in the model in accordance with the simulation conditions determined in Section 4.2.2. The fault duration is $20 \mathrm{~ms}$, which is sufficient for travelling wave protection. During the simulation process, the component named "multiple run" in PSCAD/EMTDC is applied to control the iterative simulations. The results of the $d P / d t$ amplitude are saved in every run.

\subsubsection{Calculation}

First, the amplitude of $d P / d t$ is extracted from the simulation data in Section 4.2.3. The minimum amplitude is then acquired by data processing. Finally, the minimum is divided by the reliability coefficient $K_{\text {rel }}$ to obtain the setting. On the basis of the dramatic influence of the voltage classes, $k_{1}$ is separately set by different operation voltage modes to confirm the protection sensitivity and reliability. The calculation is as follows:

$$
\begin{aligned}
& \left\{\begin{array}{l}
\left\{(d P / d t)_{\text {max }}\right\}_{\text {min }}=205.8 \mathrm{kV} / \mathrm{s} \\
(d P / d t)_{\text {set }}=\frac{\left\{(d P / d t)_{\text {max }}\right\}_{\text {min }}}{K_{\text {rel }}}=\frac{205.8}{1.1}=187.1 \mathrm{kV} / \mathrm{s}
\end{array}\right. \\
& \left\{\begin{array}{l}
\left\{(d P / d t)_{\text {max }}^{\prime}\right\}_{\text {min }}=136.3 \mathrm{kV} / \mathrm{s} \\
(d P / d t)_{\text {set }}^{\prime}=\frac{\left\{(d P / d t)_{\max }\right\}_{\text {min }}}{K_{\text {rel }}}=\frac{136.3}{1.1}=123.9 \mathrm{kV} / \mathrm{s}
\end{array}\right.
\end{aligned}
$$

$K_{\text {rel }}$ is 1.1 in this paper to take into consideration the real engineering situation, such as transformer errors, protective equipment action errors, and a security margin. $(d P / d t)_{s e t}$ is the protection setting of normal operation that DC voltage is $800 \mathrm{kV} .(d P / d t)^{\prime}$ set is the protection setting of low voltage operation that DC voltage is $400 \mathrm{kV}$.

In Section 4.2.5, the calculated setting is substituted into the travelling wave protection model to verify its sensitivity and reliability.

\subsubsection{Verification of sensitivity and reliability}

The travelling wave protection should stay inactive

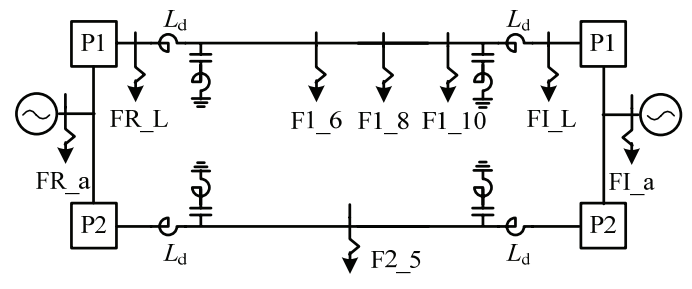

Fig. 5. Fault spots.

Table 2. Simulation action cases.

\begin{tabular}{c|c|c|c}
\hline \multicolumn{2}{c|}{ Fault spots } & Ground resistance $(\Omega)$ & $d p / d t$ \\
\hline \multirow{4}{*}{ Internal } & F1_6 & 100 & Active \\
\cline { 2 - 4 } & F1_8 & 100 & Active \\
\cline { 2 - 4 } & F1_10 & 100 & Active \\
\hline \multirow{5}{*}{ External } & F2_5 & 0 & Inactive \\
\cline { 2 - 4 } & F2_5 & 100 & Inactive \\
\cline { 2 - 4 } & FR_L & 0 & Inactive \\
\cline { 2 - 4 } & FI_L & 0 & Inactive \\
\cline { 2 - 4 } & FR_a & 0 & Inactive \\
\cline { 2 - 4 } & FI_a & 0 & \\
\hline
\end{tabular}

when external faults occur [18]. External faults include a metallic ground in the rectifier smooth reactor, a metallic ground in the inverter smooth reactor, a three-phase short circuit in the rectifier AC bus, a three-phase short circuit in the inverter AC bus, and a metallic ground in other DC transmission line [21]. In the verification of the sensitivity and reliability, both internal and external faults should be considered.

The fault spots are given in Fig. 5, and the results of the verification are shown in Table 2 . It can be seen that the setting calculated by the proposed procedure achieves the protection requirement.

\subsection{Effectiveness analysis of the proposed method}

The proposed method in this paper has been applied to the real XS HVDC projects. The protection setting obtained by this method needs to be tested and adjusted slightly by RTDS closed-loop platform.

The main circuit model of XS HVDC project in this case is built in RSCAD. The structure, main parameters and simulation time step of this model are the same with those of model in PSCAD/EMTDC in Section 4.1. The real control and protection equipment is connected to the RTDS using the input/output cards, and control the main circuit model in RSCAD in real time.

The real protection settings are finally determined after the test on RTDS platform. The settings of travelling wave protection in real XS projects are $180 \mathrm{kV} / \mathrm{s}$ in normal operation and $110 \mathrm{kV} / \mathrm{s}$ in low voltage operation. The corresponding protection settings obtained by the proposed method are $187.1 \mathrm{kV} / \mathrm{s}$ and $123.9 \mathrm{kV} / \mathrm{s}$ (in 4.2.4), which are close to that of real projects. The comparisons of other protection settings are also analyzed. The results show the proposed method is effective. 


\section{HVDC Protection Setting System}

To improve the efficiency of the setting procedure, this paper developed an HVDC protection setting system programmed in the $\mathrm{C \#}$ language. The system structure is given in Fig. 6.

The input data of this system include the simulation model parameters, simulation data, and related parameters of the primary equipment. All data should be stored in relevant files and formats, so that the system can automatically read data and make setting. The model in

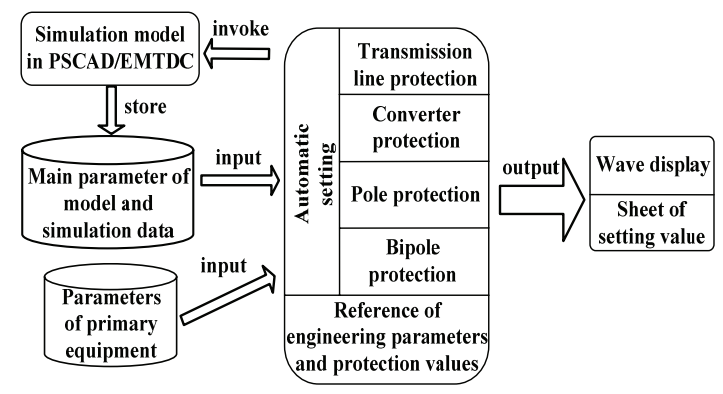

Fig. 6. Structure of HVDC protection setting system

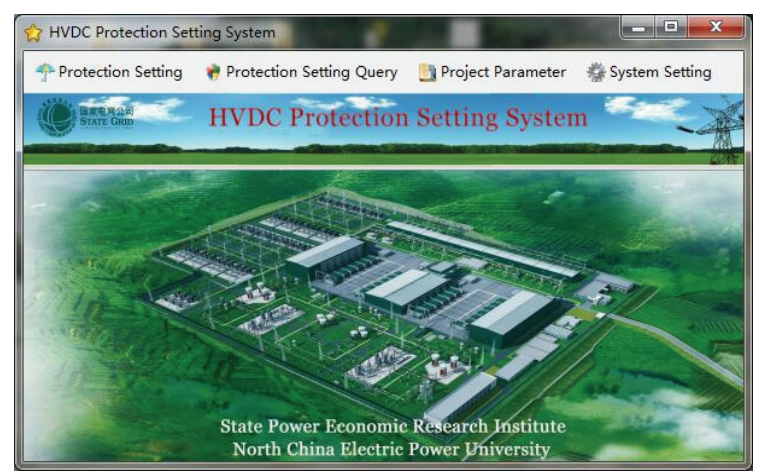

(a)

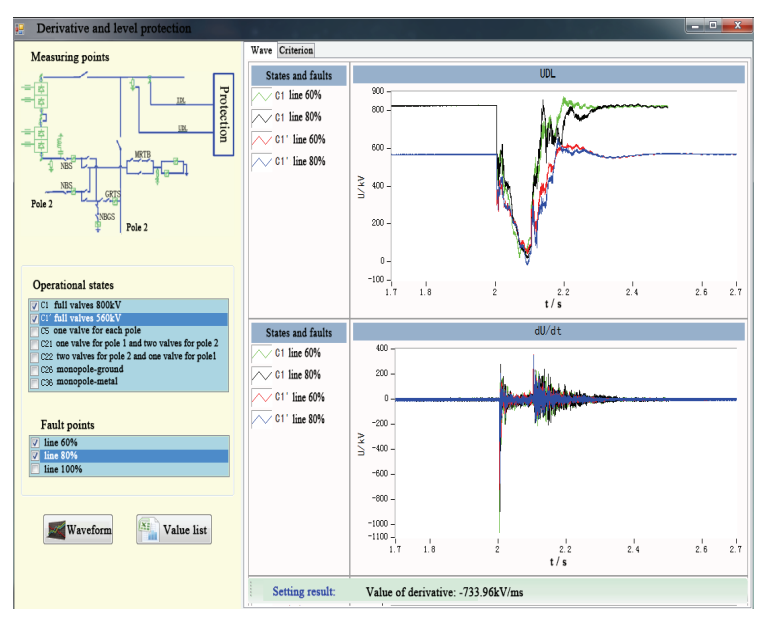

(c)
PSCAD/EMTDC can be directly invoked by this system. The simulation is repeated according to the simulation conditions, and the protection setting is automatically obtained by analyzing the simulation results.

In addition to the function of automatic protection setting, the system also has some auxiliary functions, such as waveform display, data management, and querying of HVDC projects. The typical interfaces of HVDC protection setting system are given in Fig. 7.

This HVDC protection setting system has been successfully applied to HVDC projects of the State Grid Corporation of China.

\section{Conclusions}

This paper focuses on protection setting in an HVDC system. To facilitate protection setting, a new classification of HVDC protections is presented according to the protection theories. The HVDC protections are divided into six categories. Aiming at protections designed to eliminate certain faults, including travelling wave protection, derivative and level protection, and differential protection,

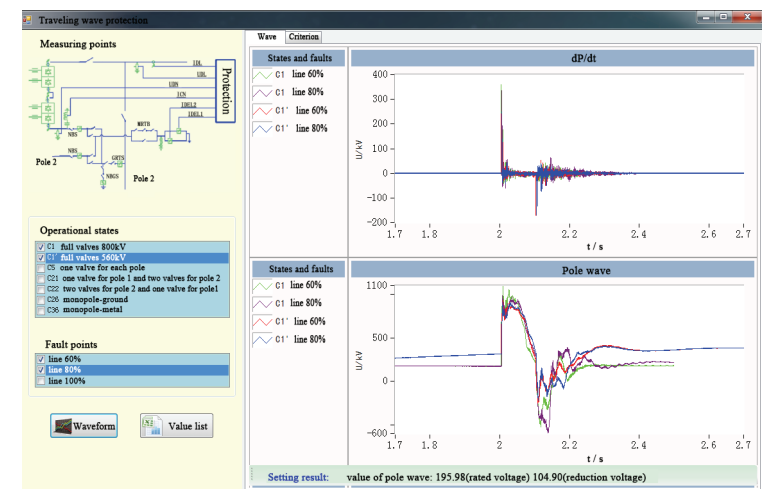

(b)

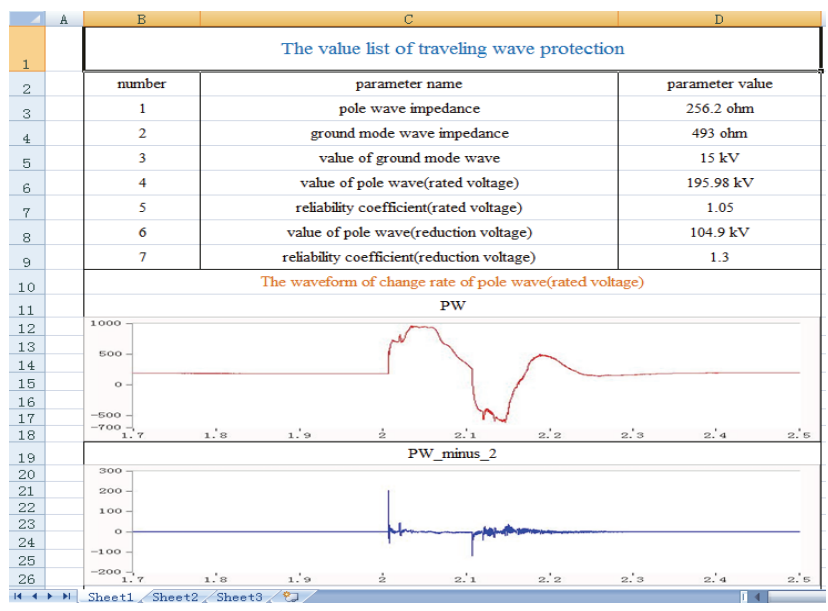

(d)

Fig. 7. Interfaces of HVDC protection setting system: (a) main interface; (b) interface of travelling wave protection; (c) interface of derivative and level protection; (d) screenshot of value list of traveling wave protection. 
this paper proposes a novel procedure for protection setting based on fault quantities. Travelling wave protection of the $\mathrm{XS}$ project is taken as an example to show the application of the setting procedure. An HVDC protection setting system is developed by using the $\mathrm{C \#}$ programming language to improve the efficiency. The proposed procedure and the HVDC protection setting system have been applied in real HVDC projects and greatly improved the efficiency of protection setting.

\section{Appendix}

Table A. Main circuit parameters

\begin{tabular}{|c|c|c|}
\hline \multicolumn{2}{|r|}{ Parameters } & Values \\
\hline \multirow{9}{*}{$\begin{array}{c}\mathrm{DC} \\
\text { transmission } \\
\text { line }\end{array}$} & Line length & $1935 \mathrm{~km}$ \\
\hline & Tower height & $28 \mathrm{~m}$ \\
\hline & Spacing between phases & $21 \mathrm{~m}$ \\
\hline & Shunt conductance & $1.0 \mathrm{E}-11 \mathrm{mohs} / \mathrm{m}$ \\
\hline & Conductor radius & $0.0181 \mathrm{~m}$ \\
\hline & Conductor DC resistance & $0.03984 \mathrm{ohm} / \mathrm{km}$ \\
\hline & SAG for all conductors & $0 \mathrm{~m}$ \\
\hline & $\begin{array}{c}\text { Number of sub-conductors in } \\
\text { a bundle }\end{array}$ & 6 \\
\hline & Bundle spacing & $0.45 \mathrm{~m}$ \\
\hline \multirow{4}{*}{$\begin{array}{l}\text { Rectifier/ } \\
\text { inverter } \\
\text { AC system }\end{array}$} & Rated voltage & $530 \mathrm{kV} / 515 \mathrm{kV}$ \\
\hline & Frequency & $50 \mathrm{~Hz} / 50 \mathrm{~Hz}$ \\
\hline & Equivalent resistance & $0.9075 \mathrm{ohm} / 0.275 \mathrm{ohm}$ \\
\hline & Equivalent inductance & $0.055 \mathrm{H} / 0.0175 \mathrm{H}$ \\
\hline \multirow{5}{*}{$\begin{array}{l}\text { Rectifier/ } \\
\text { inverter } \\
\text { converter } \\
\text { transformer }\end{array}$} & Rated capacity & 963.3 MVA / 891.3 MVA \\
\hline & Ratio & $\begin{array}{c}530.3 / 170.3 \mathrm{kV} / \\
515.0 / 157.6 \mathrm{kV} \\
\end{array}$ \\
\hline & $\begin{array}{l}\text { Positive sequence leakage } \\
\text { reactance }\end{array}$ & 0.18 p.u. $/ 0.167$ p.u. \\
\hline & No load losses & $\begin{array}{l}0.00059 \text { p.u. } / 0.00063 \\
\text { p.u. }\end{array}$ \\
\hline & Copper losses & $\begin{array}{c}0.00235 \text { p.u. / } 0.00217 \\
\text { p.u. }\end{array}$ \\
\hline \multirow{4}{*}{$\begin{array}{l}\text { Rectifier/ } \\
\text { inverter } \\
\text { converter } \\
\text { valve }\end{array}$} & Thyristor ON resistance & $\begin{array}{c}0.0096 \mathrm{ohm} / 0.00874 \\
\mathrm{ohm}\end{array}$ \\
\hline & Thyristor OFF resistance & 3.0E6 ohm / 3.5E6 ohm \\
\hline & Snubber capacitance & $0.0267 \mathrm{uF} / 0.0393 \mathrm{uF}$ \\
\hline & Snubber resistance & $2160 \mathrm{ohm} / 1680 \mathrm{ohm}$ \\
\hline
\end{tabular}

Table B. Detailed parameters of operation modes

\begin{tabular}{c|c|c|c|c}
\hline Operation mode & $\begin{array}{c}\text { Pole 1 } \\
\text { voltage }\end{array}$ & $\begin{array}{c}\text { Pole 2 } \\
\text { voltage }\end{array}$ & $\begin{array}{c}\text { DC } \\
\text { current }\end{array}$ & Power \\
\hline Rated operation & $+800 \mathrm{kV}$ & $-800 \mathrm{kV}$ & $4 \mathrm{kA}$ & $6400 \mathrm{MW}$ \\
\hline $\begin{array}{c}\text { Reduction voltage } \\
\text { operation }\end{array}$ & $+560 \mathrm{kV}$ & $-560 \mathrm{kV}$ & $4 \mathrm{kA}$ & $4480 \mathrm{MW}$ \\
\hline $\begin{array}{c}\text { Monopole-ground } \\
\text { operation }\end{array}$ & $+800 \mathrm{kV}$ & 0 & $4 \mathrm{kA}$ & $3200 \mathrm{MW}$ \\
\hline $\begin{array}{c}\text { Monopole-metal } \\
\text { operation }\end{array}$ & $+800 \mathrm{kV}$ & 0 & $4 \mathrm{kA}$ & $3200 \mathrm{MW}$ \\
\hline $\begin{array}{c}\text { Bipolar converters } \\
\text { outage }\end{array}$ & $+400 \mathrm{kV}$ & $-400 \mathrm{kV}$ & $4 \mathrm{kA}$ & $3200 \mathrm{MW}$ \\
\hline $\begin{array}{c}\text { Pole } 1 \text { converters } \\
\text { outage }\end{array}$ & $+400 \mathrm{kV}$ & $-800 \mathrm{kV}$ & $4 \mathrm{kA}$ & $4800 \mathrm{MW}$ \\
\hline $\begin{array}{c}\text { Pole } 2 \text { converters } \\
\text { outage }\end{array}$ & $+800 \mathrm{kV}$ & $-400 \mathrm{kV}$ & $4 \mathrm{kA}$ & $4800 \mathrm{MW}$ \\
\hline
\end{tabular}

\section{References}

[1] R. Rudervall, J. P. Charpentier, R. "Sharma. High voltage direct current (HVDC) transmission systems technology review paper," Energy week 2000, 5.

[2] M. Karthikeyan, Y. M. Yeap, A. Ukil. "Simulation and analysis of faults in high voltage DC (HVDC) power transmission," IECON 2014 - 40th Annual Conference of the IEEE, pp. 1786-1791, 2014.

[3] P. Bresesti, W. L. Kling, R. L. Hendriks, R. Vailati. "HVDC connection of offshore wind farms to the transmission system," IEEE Trans. Energy Conversion, vol. 22, pp. 37-43, 2007.

[4] Y. P. Li, D. G. Wang, A. P. Hu, W. Wang, Z. Q. Yao. "Real-time simulation study on HVDC control and protection," 2010 International Conference on Power System Technology, pp. 1-6, 2010.

[5] M. Ikhide, S. Tennakoon, A. Griffiths, S. Subramanian, H. Ha. "Fault detection in Multi-Terminal Modular Multilevel Converter (MMC) based High Voltage DC (HVDC) transmission system," IEEE Power Engineering Conference 2015 50th International University, pp. 1-6, 2015.

[6] A. Hamerulaine, S-A Zidi, A. Kouzou, M.A. Djehaf. "Improvement of the HVDC link performances based on the protection functions," IEEE international Conference on Industrial Technology, pp. 2714-2720, 2015.

[7] Rui Li, Lie Xu, D. Holliday, F. Page, S J. Finney, B. W. Williams. "Continuous operarion of radial multitermianl HVDC systems under DC fault," IEEE Transactions on Power Delivery, vol. 31, pp. 351-361, 2016.

[8] J. Sneath, A. Rajapakse. "Fault detection and interruption in an earthed HVDC grid using ROCOV and hybrid DC breakers," IEEE Power \& Energy Society General Meeting, pp. 1-1, 2015.

[9] Shuxin Luo, Xinzhou Dong, Shenxing Shi, Bin Wang. "A directional protection scheme for HVDC transmission on lines based on reactive energy," IEEE transactions on Power Delivery, vol. 30, pp.1-9, 2015.

[10] Zhao Li, Guibin Zou, Bingbing Tong, Houlei Gao, Qian Feng. "Novel traveling wave protection method for high voltage DC transmission line," IEEE Power \& Energy Society General Meeting, pp.1-5, 2015.

[11] B. Geebelen, W. Leterme, D. Van Hertem. "Analysis of DC breaker requirements for different HVDC grid protection schemes," IET International Conference on AC and DC Power Transmission, pp.1-7, 2015.

[12] J. Jin. "Protection of HVDC transmission lines based on wavelet transformation and analysis of energy spectrum," 2013 2nd International Symposium on Instrumentation and Measurement, Sensor Network and Automation, pp. 180-185, 2013.

[13] D. Naidoo, N.M. Ijumba. "A protection system for 
long HVDC transmission lines," IEEE Power Engineering Society Inaugural 2005 Conference and Exposition in Africa, pp. 150-155, 2005.

[14] H. A. Darwish, M. A. Rahman, A. I. Taalab, H. Shaaban. "Overcurrent relay with novel characteristics for HVDC converter protection," Electrical and Computer Engineering, vol.2, pp. 664-667, 1995.

[15] T. X. Zhu, H. Y. Zhou, J. Yu, J. Y. Huang. "The analysis on a successive forced outage in chu-sui HVDC system caused by DC line fault," IEEE PES Transmission and Distribution Conference and Exposition (T\&D), pp. 1-4, 2012.

[16] J. L. Suonan, S. P. Gao, G. B. Song, Z. B. Jiao, X. N. Kang. "A novel fault-location method for HVDC transmission lines," IEEE Trans. Power Deliv., vol. 25, pp. 1203-1209, 2010.

[17] D.H. Liu, Y.H. Li, D.Y. Shi, C. Fu, X.Z. Duan. "Study on setting preparative parameter of HVDC system protection," Automation of Electric Power System, vol. 35, pp. 47-51, 2011.

[18] X. Liu, A.H. Osman, O.P. Malik. "Hybrid traveling wave/boundary protection for monopolar HVDC line," IEEE Trans. Power Deliv., vol. 24, pp. 569-578, 2009.

[19] Huang Zhiling, Tian Jie. "EMTDC simulation of based on detailed control model of HVDC system," Automation of Electric Power System, vol. 32, pp. 4548, 2008.

[20] D. Naidoo, N.M. Ijumba. "HVDC line protection for the proposed future HVDC systems," International Conference on Power System Technology, vol. 2, pp. 1327-1332, 2004.

[21] K. L. Han, Z. X. Cai, Y. Liu. "Study on protective performance of HVDC transmission line protection with different types of line fault," Electric Utility Deregulation and Restructuring and Power Technologies, pp. 358-361, 2011.

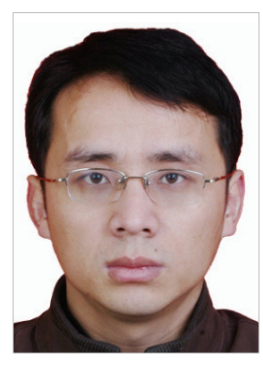

Benfeng Gao He received his M.S. and $\mathrm{Ph} . \mathrm{D}$. degrees in electrical engineering from North China Electric Power University, China in 2007 and 2011, respectively. Since 2011, he has been with the Department of Electrical Engineering, North China Electric Power University, where he is currently working as a lecturer. His research interests include power system sub-synchronous oscillation and control and protection of HVDC system.

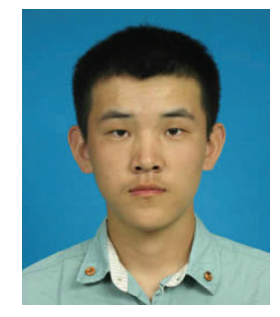

Ruixue Zhang He received his B.S. degree from North China Electric Power University, China in 2016. He is current pursuing M.S. degree in the Department of Electrical Engineering, North China Electric Power University. His research interests are control and protection of HVDC system and power system operation and control.

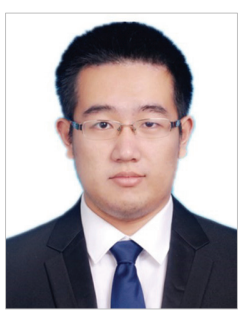

Xuewei Zhang He received his B.S. degree in electrical engineering from North China Electric Power University, China in 2014. Since 2014, he has been studying for a M.S. degree in the Department of Electrical Engineering, North China Electric Power University. His research interests include control and protection of HVDC system and wind power system. 